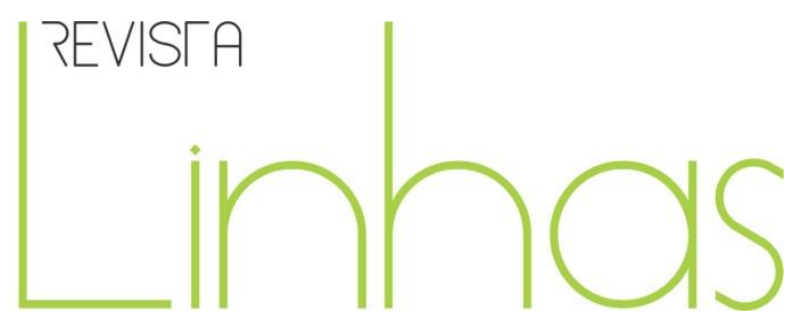

\title{
O lugar do Atendimento Educacional Especializado nas práticas culturais de escolarização em contextos de inclusão escolar ${ }^{1}$
}

\begin{abstract}
Resumo
Este artigo problematiza a contradição entre os conceitos de transversalidade da Educação Especial e de complementaridade/ suplementaridade do Atendimento Educacional Especializado (AEE) na escolarização do público-alvo da Educação Especial. Tomam-se como objeto de discussão as orientações da política de Educação Especial, os estudos sobre práticas culturais de escolarização e de elaboração conceitual no AEE e na sala comum de ensino. $O$ trabalho resulta de estudos do Observatório de escolarização de alunos com deficiência intelectual em redes municipais de ensino de dois estados brasileiros (Santa Catarina e Rio de Janeiro). Esses estudos têm evidenciado um modelo de escola, com práticas culturais de escolarização marcadas por espaços e tempos escolares dicotomizados, os quais normatizam o trabalho docente, definem as relações de ensino e aprendizagem e distanciam o trabalho do AEE da sala comum. Em um espaço, organiza-se o trabalho pelo uso de recursos, e, em outro, pelos conteúdos. Um privilegia atividades específicas às necessidades do aluno, e o outro o insere em um espaço comum, sem diferenças de tratamento, de metodologias e de recursos. Não havendo conexão entre ambos, reduz-se a compreensão de escolarização à instrumentação e ao conteúdo, significados estes produzidos tanto pela política quanto pela cultura e traduzidos no currículo. Em face desse modelo, indaga-se sobre as efetivas condições de O AEE atuar como complementar ou suplementar às práticas culturais de escolarização e, por outra via, sobre as possibilidades de constituir espaços convergentes de escolarização entre o AEE e a sala comum pela elaboração de conceitos.
\end{abstract}

Palavras-chave: Política Educacional; Escolarização; Deficiência Intelectual; Inclusão Escolar; Educação Especial.

\section{Cristiane da Silva}

Secretaria Municipal de Educação de Itajaí - SC/Brasil

cristiane.itajai@yahoo.com.br

Regina Célia Linhares Hostins

Universidade do Vale do Itajaí UNIVALI - SC/Brasil reginalh@univali.br

Regina da Silva Mendes Secretaria Municipal de Educação de Balneário Camboriú - SC/Brasil reginamendes1@hotmail.com

\section{Para citar este artigo:}

SILVA, Cristiane da; HOSTINS, Regina Célia Linhares; MENDES, Regina da Silva. O lugar do Atendimento Educacional Especializado nas práticas culturais de escolarização em contextos de inclusão escolar Revista Linhas. Florianópolis, v. 17, n. 35, p. 10-29, set./dez. 2016.

DOI: $10.5965 / 1984723817352016010$

http://dx.doi.org/10.5965/1984723817352016010

\footnotetext{
${ }^{1}$ Estudo resultante de pesquisa subsidiada pelos órgãos financiadores: OBEDUC/ CAPES, FAPERJ e CNPq, período 20142017.
} 


\title{
The place of the Specialized Education Service in cultural practices of schooling in school inclusion contexts
}

\begin{abstract}
This paper problematizes the contradiction between the concepts of transversality of Special Education and complementarity/supplementarity of Specialized Education Service (SES) in schooling the target audience of Special Education. We took as object of discussion the guidelines of the special education policy, studies on cultural practices of schooling and school experiences of conceptual elaboration in the SES and the common classroom. The work results from studies of the schooling Observatory of students with intellectual disabilities in municipal education networks of two Brazilian states (Santa Catarina and Rio de Janeiro). These studies have shown a school model with cultural practices of schooling marked by dichotomized school space and time, which standardizes the teaching work, defines relationships of teaching and learning and distances the work of the SES teacher in the common classroom. In one space the work is organized with the use of resources, and in the other with the content. One favors specific activities to the needs of the students, and the other inserts in a common space, without differences in treatment, methodologies and resources. With no connection between them, the understanding of schooling is reduced to instrumentation and content, meanings produced both by politics and culture and translated into the curriculum. Given this model, we inquire about the effective conditions of the SES acting as complementary or supplementary in relation to the cultural practices of schooling and, in addition, about the possibilities of constituting converging spaces of education between the SES and the common classroom for the elaboration of concepts.
\end{abstract}

Keywords: Education Policy; Schooling; Intellectual Disabilities; Special Education; School Inclusion. 


\section{Introdução}

As políticas de educação inclusiva vêm sendo amplamente discutidas em âmbito mundial desde a década de 1990, oriundas tanto das demandas de organizações e movimentos sociais em defesa dos direitos humanos, como de redes políticas internacionais que propagavam as reformas do Estado, com destaque para as reformas educacionais.

No Brasil, particularmente em relação à inclusão escolar do público-alvo da Educação Especial, as políticas implantadas no período tiveram como referência medidas deliberadas em grandes conferências lideradas, em sua maioria, por organismos multilaterais como a Organização das Nações Unidas, o Banco Mundial e a UNESCO. Nesse âmbito, merecem destaque: a Conferência Mundial de Educação para Todos, em Jomtien (1990), a Conferência Mundial de Necessidades Educativas Especiais: Acesso e Qualidade, que resultou na assinatura da Declaração de Salamanca (1994) e a Convenção Interamericana para a Eliminação de Todas as Formas de Discriminação contra as Pessoas Portadoras de Deficiência que promulgou a Declaração de Guatemala (1999).

Na década de 2000, a inclusão escolar ganhou mais densidade com a aprovação da Política Nacional de Educação Especial na Perspectiva da Educação Inclusiva (BRASIL, 2008), em cujo documento o governo brasileiro expressa os compromissos assumidos em 2006, na Convenção Internacional sobre os Direitos das Pessoas com Deficiência, da Organização das Nações Unidas, em Nova York. Nessa Convenção, os Estados Partes reconheceram (artigo 24), o direito das pessoas com deficiência à educação em um sistema educacional inclusivo em todos os níveis de ensino e em igualdade de condições com as demais pessoas na comunidade em que vivem. O Brasil ratificou seu compromisso com uma emenda constitucional, por meio do Decreto Legislativo $n^{\circ}$ 186/2008 e pelo Decreto Executivo n 6.949/2009.

Com base nesse pressuposto e compromisso, a Política Nacional de Educação Especial na Perspectiva da Educação Inclusiva (BRASIL, 2008) apresenta os referenciais nacionais para a construção de sistemas educacionais e a organização de escolas inclusivas, define o público-alvo da Educação Especial - alunos com deficiência, transtornos globais do desenvolvimento e altas habilidades/superdotação - e delimita a 
natureza do Atendimento Educacional Especializado (AEE) no processo de inclusão escolar. Entre suas diretrizes, a política propõe:

- a transversalidade da modalidade de educação especial - da educação infantil à educação superior;

- a oferta do Atendimento Educacional Especializado - AEE como complementar e/ou suplementar à escolarização dos alunos, por meio da Sala de Recursos Multifuncional SRM;

- a formação de professores para AEE e demais profissionais da educação para a inclusão e a participação da família e da comunidade;

- acessibilidade arquitetônica, nos transportes, nos mobiliários, nas comunicações e informação; e

- a articulação intersetorial na implementação das políticas públicas. (BRASIL, 2008, p. 8)

De acordo com o texto da política, o AEE assume a função de "[...] identificar, elaborar e organizar recursos pedagógicos e de acessibilidade que eliminem as barreiras para a plena participação dos alunos, considerando suas necessidades específicas" (BRASIL, 2008, p. 10). As atividades desenvolvidas nesse espaço devem ser diferenciadas das realizadas na sala de aula comum, complementando e/ou suplementando a formação dos alunos.

Desse modo, a partir do conjunto de diretrizes estabelecidas e das definições dos papéis e das funções dos atores envolvidos, a política define como meta principal fortalecer o modelo educacional inclusivo garantindo não somente o acesso desse público-alvo ao ensino comum, mas, principalmente, a sua permanência, estabelecendo as trocas capazes de promover a participação, o aprendizado e o desenvolvimento.

No quesito do acesso, a partir de 2008, observou-se, de fato, expressivo avanço, o qual se evidenciou na transição do número de alunos matriculados em escolas e classes especiais para o ensino regular. Dados do Censo Escolar de 2013 indicaram que, no país, em 2008, haviam registradas 319.924 matrículas em escolas/classes especiais, contra 375.775 matrículas desse público nas classes comuns. Em 2013, por sua vez, registraram-se 194.421 matrículas nas escolas/classes especiais e um total significativo de 648.921 matriculas nas classes comuns. Do ponto de vista da permanência ou da participação e aprendizado desses alunos, todavia, há outros fatores qualitativos a serem considerados 
e discutidos tanto do ponto de vista da orientação da política, como da sua tradução no contexto da escola.

Decorridos oito anos de funcionamento da política e considerando os diferentes contextos em que ela opera, a proposta é discutir suas diretrizes e problematizar seus conceitos, tendo por base a compreensão de que políticas são sempre traduzidas, reconstruídas e refeitas entre "diversos atores, textos, tecnologias e objetos (artefatos)" (BALL; MAGUIRE; BRAUN, 2012, p. 3) no interior da escola.

Em face desse pressuposto, é propósito deste artigo discutir a contradição entre as diretrizes de transversalidade da Educação Especial e as de complementaridade ou suplementaridade do AEE na escolarização do público-alvo da Educação Especial. Indagam-se as possibilidades de, na prática, essas orientações da política, no lugar de garantirem a transversalidade, ampliarem a cisão entre o ensino comum e o ensino especializado e de comprometerem o processo de inclusão escolar no que se refere à participação e à aprendizagem do seu público-alvo.

De modo particular, busca-se problematizar o lugar e o papel do AEE no processo de escolarização, tomando como objeto de discussão as orientações da política de Educação Especial, os estudos sobre práticas culturais de escolarização e de elaboração conceitual na escola como uma das possibilidades de se pensar práticas convergentes e transversais de inclusão escolar.

Este trabalho é resultado dos estudos empreendidos no âmbito da pesquisa sobre A escolarização de alunos com deficiência intelectual: políticas públicas, processos cognitivos e avaliação da aprendizagem, vinculada ao Programa Observatório de Educação (OBEDUC/CAPES), o qual conta com uma equipe de pesquisadores - professores e estudantes de Pós-Graduação em educação, alunos de iniciação científica e professores de Educação Básica e Especial. A pesquisa envolve os Programas de Pós-Graduação da Universidade Federal Rural do Rio de Janeiro (UFRRJ), Universidade do Vale do Itajaí (UNIVALI) e Universidade do Estado de Santa Catarina (UDESC). 


\section{Qual o lugar e o papel do AEE no processo de inclusão escolar e de escolarização?}

Ball (1994) afirma que é necessário olhar tanto para os efeitos específicos de determinadas políticas, como para os efeitos cumulativos ou gerais de conjuntos de políticas. O exercício que se deseja neste item é discutir os possíveis efeitos específicos e cumulativos de uma política que, buscando a inclusão escolar e a transversalidade da Educação Especial, define para ela papéis e tarefas periféricas, complementares e segmentadas em relação ao lócus e aos processos de escolarização que, por sua natureza, constituem a ontologia da escola.

O documento da política (BRASIL, 2008, p. 16) define que o AEE deve ser "[...] organizado para apoiar o desenvolvimento dos alunos, constituindo oferta obrigatória dos sistemas de ensino e deve ser realizado no turno inverso ao da classe comum, na própria escola ou centro especializado que realize esse serviço educacional". Para a organização do serviço nas escolas, nos anos subsequentes à publicação da política, foram publicados recursos normativos e documentos orientadores disciplinando o seu funcionamento. Entre eles, destacam-se a Resolução CNE/CEB n 4/2009, que institui as Diretrizes Operacionais para o Atendimento Educacional Especializado na Educação Básica, modalidade Educação Especial; o Manual de Orientação do Programa de Implantação de Sala de Recursos Multifuncionais de 2010; e o Decreto n 7.611/2011, que dispõe sobre o Atendimento Educacional Especializado e define a distribuição dos recursos do Fundo de Manutenção e Desenvolvimento da Educação Básica - FUNDEB, admitida a dupla matrícula dos estudantes na educação regular e no Atendimento Educacional Especializado.

O Decreto $n^{\circ} 7.611$, de 17 de novembro de 2011 , volta a enfatizar, no art. $2^{\circ}, \S 1^{\circ}$, que o AEE deve ser compreendido como o conjunto de atividades, recursos de acessibilidade e pedagógicos organizados institucional e continuamente, prestado de forma:

I - complementar à formação dos estudantes com deficiência, transtornos globais do desenvolvimento, como apoio permanente e limitado no tempo e na frequência dos estudantes às salas de recursos multifuncionais; ou 
II - suplementar à formação de estudantes com altas habilidades ou superdotação. (BRASIL, 2011, p. 12)

Na sequência, no art. $3^{\circ}$ desse Decreto (BRASIL, 2011), definem-se os objetivos do $\mathrm{AEE}$, entre os quais se destacam: prover condições de acesso, de participação e de aprendizagem no ensino regular; garantir a transversalidade das ações da Educação Especial no ensino regular e fomentar o desenvolvimento de recursos didáticos e pedagógicos. O serviço pode efetivamente alcançar tais objetivos, centrais no processo de inclusão, ocupando uma função periférica no processo educacional?

Não se desconhece $o$ fato de que a ênfase da política na complementaridade/suplementaridade visava romper com a concepção, de certa forma, sacralizada na educação em geral, de que a Educação Especial seria substitutiva da primeira, ideia que em si comprometia fortemente os processos de inclusão escolar. No entanto, no intuito de romper com o isolamento da substituição, optou-se pelo risco da posição acessória e instrumental no processo educacional.

Entre o conceito de transversalidade e o de complementaridade, parece haver um embate ou uma negação. Se o primeiro quer significar um novo lugar para a Educação Especial e uma relação longitudinal e intrínseca entre ela e todos os níveis de ensino, o segundo atribui à Educação Especial um não lugar, ou um lugar complementar na escola ou, ainda, uma função que, por se pautar na provisão de recursos, atua como complemento nas relações e nas práticas culturais de escolarização.

Há de indagar-se, ainda, se a política ao assumir essa posição, não estaria contribuindo para aprofundar o distanciamento e o isolamento da relação Educação Especial e educação regular e, também, para o descolamento das práticas pedagógicas da Sala de Recursos Multifuncionais (SEM) e das práticas de escolarização nas salas comuns de ensino? Os efeitos dessa política podem contribuir, contraditoriamente, para o fortalecimento do ensino individualizado do aluno público-alvo da Educação Especial na SRM.

O papel atribuído ao professor do AEE na política também merece destaque. A legislação orienta que a formação inicial o habilite para o exercício da docência e que este 
possua formação específica em Educação Especial. Diante dessa proposição, ele tem se tornado o detentor do saber sobre os alunos com deficiência, transtornos globais do desenvolvimento e altas habilidades, "um ser multifuncional”, como define Garcia (2013, p. 115).

O professor especializado parece ser responsável por promover a inclusão em todos os seus aspectos. No contexto da escola, ele é visto como aquele que possui o conhecimento necessário para fazer com que os alunos aprendam e o professor do ensino regular, que não possui tal conhecimento, na maioria dos casos, pode se eximir dessa tarefa.

De acordo com a política, o professor de AEE tem por “[...] função identificar, elaborar e organizar os recursos pedagógicos e de acessibilidade que eliminem as barreiras para a plena participação dos alunos, considerando suas necessidades específicas" (BRASIL, 2008, p. 10). No documento, evidencia-se a responsabilidade do professor pela provisão dos recursos que possam facilitar a participação do aluno no processo de aprendizagem. Na prática, não fica clara a relação de transversalidade com o ensino comum, nem o papel dos demais atores nesse processo, aumentando o abismo existente entre todos os profissionais da escola, cujas práticas pedagógicas deveriam ser convergentes no caminho da escolarização, como afirmam Hostins e Jordão:

A complementariedade ou suplementariedade de um serviço ou de uma atribuição docente no contexto da escola delimita as margens de ação, distingue os papéis e espaços de ensino e, contraditoriamente, como um processo de inclusão às avessas, contribui para aumentar o fosso entre o ensino regular e especial, entre o professor do atendimento especializado e o professor do ensino comum. (HOSTINS; JORDÃO, 2014, p. 7)

Contudo, quais os modos possíveis de romper com o distanciamento? Como se constrói no pensamento coletivo da escola as possibilidades de atuar coletiva ou separadamente no processo de escolarização? Ou melhor, que conceito e que práticas culturais de escolarização são relevantes para a participação e a aprendizagem de todos na escola? 


\section{Afinal, o que significa a escolarização e como o AEE dela participa?}

O que está se propondo neste item é a ampliação do olhar sobre os processos de escolarização na escola inclusiva para pensá-los não como lugares específicos e polarizados, nesse caso, a classe comum e a especializada, mas colocar em questão o “núcleo duro" da organização pedagógica da escola em que são distribuídos papéis, estratégias e espaços compartimentados, com divisões fixas, no qual predominam, de um lado, a cultura de uma classe em que se ensina a muitos como se fossem um só (BARROSO, 2013) e, de outro, a cultura de uma classe em que se ensina a poucos, como se fossem sós. De um lado, a cultura centrada nos conteúdos compartimentados das

salas comuns e, de outro, a cultura centrada no uso de recursos da SRM, totalmente desprovidos de conteúdo. "Uma escola que é pensada para igualar os sujeitos, e para isso se guia por princípios que visam homogeneizar os saberes, as práticas e por fim os alunos desenvolve um precoce processo de individualização, marcando trajetórias e criando desigualdades em seu contexto" (LUNARDI, 2004, p. 63).

Dussel (2014) discute questões dessa natureza trazendo para análise a relação entre os conceitos de autoridade cultural e de currículo. A autora considera que a escola, em geral, constitui uma autoridade cultural que autoriza, reconhece e valoriza certas práticas culturais ao passo que desqualifica outras.

Qué conocimientos se van a considerar relevantes, qué metodologías y discursos se jerarquizan como legítimos, quiénes pueden enseñar y quiénes aprender, son todos elementos centrales de esta autoridad cultural, que puede ser más o menos inclusiva, o más o menos democrática, según cómo se articule a otras dinâmicas sociales. (DUSSEL, 2014, p. 4)

A política na sua configuração articula-se e contribui para essa dinâmica social, mas não significa que todas as escolas tomem a sua orientação de maneira linear e acrítica, nem tampouco que o AEE seja exatamente igual em todas as escolas. Há, nesse espaço, outras redes de relações, outros discursos e práticas que vão delineando de maneira muito própria a autoridade cultural e as respostas às orientações da política. 
Desse modo, é possível encontrar escolas mais ou menos inclusivas, mais ou menos democráticas nas quais as fronteiras entre os espaços são diluídas e todos se sentem responsáveis pela participação, aprendizagem e desenvolvimento de todos. Há outras, porém, cujas fronteiras são rigidamente delimitadas, onde há pouco espaço para cooperação, para um projeto de escolarização ampliado e para o diferente.

Nesse sentido, pode-se falar como afirma Gimeno Sacristán (1997, p. 34), em "reconstruções escolares da cultura externa", manifestas no projeto de escolarização definidos pela escola, em que se definem suas pautas do comportamento, seu pensamento e sua organização. Embora relacionada ao que ocorre no pano de fundo externo, há códigos e mecanismos tipicamente escolares, motivo pelo qual a cultura curricularizada passa a ser um artefato especial, com significado próprio.

Assim, em escolas nas quais as classes comuns de ensino e a SRM constituem espaços e propósitos distintos e apartados em relação à escolarização dos alunos, elas expressam comportamentos, pensamentos e organizações mais excludentes que inclusivas. "A cultura moldada pelo currículo constitui um quadro e um conjunto de significados para a socialização dos alunos, mas não o será menos para o comportamento dos professores" (GIMENO SACRISTÁN, 1997, p. 35). Segundo Dussel,

Esta separación o diferenciación de saberes ha sido llamada por Basil Bernstein como "curriculum de colección", con contenidos claramente separados entre sí y con profesores especializados que, aunque pueden compartir un mismo ideal, sin embargo se sostienen en espacios autónomos y diferenciados. (DUSSEL, 2014, p. 9)

Nessa reconfiguração cultural, não apenas o ensino é excludente, mas também as práticas, as relações entre os atores e seus comportamentos. Para compreender melhor essa problemática, Lunardi (2012) faz uma reflexão acerca das práticas pedagógicas desenvolvidas por professores em classes comuns de ensino nas quais há alunos com deficiência. Ela denuncia a "polarização” entre a prática com os alunos com deficiência e a prática com os alunos sem deficiência nesse espaço. A autora considera, no entanto, que essas práticas curriculares não são ações individualizadas, mas a expressão de uma cultura, construída historicamente, que permeia e organiza os espaços e tempos 
escolares, que normatiza o trabalho docente, e, consequentemente, as relações de ensino e aprendizagem no espaço escolar.

Isso também é marcado na organização do espaço escolar para atender ao público da Educação Especial, que, apartado da escola, traz uma proposta de ensino pelo uso de recursos e aparatos, utilizados nas salas de recursos. Entretanto, essas práticas são também expressão dos usos e dos significados produzidos tanto pela política quanto pela cultura da Educação Especial, que se materializa no currículo centrado em atividades intelectivas, motoras e absolutamente individualizadas. Tudo isso se traduz nas práticas pedagógicas, no comportamento dos docentes e, também, dos alunos, que identificam a diferenciação de tratamento, reforçando, muitas vezes, a concepção de que com o outro tudo deve ser diferente, gerando ainda mais exclusão.

Tendo consciência desse processo e sabendo que ele pode ser diferente, pode-se pensar em decodificar as condições de escolarização desse currículo dominante. Para Gimeno Sacristán (1997), significa decodificar o tipo de cultura que se pode transmitir e a que se transmite, de fato, por meio das instituições. Vislumbram-se, aqui, novas possibilidades de compreensão da escolarização que supõe falar de formas alternativas aos comportamentos pedagógicos, organizacionais e institucionais sacralizados. Dito de outra forma, “[...] a alternativa à escolarização dominante para um projeto cultural diferente, implica um constante esforço por decodificar as condições da escolarização, porque sem a transformação dessas condições não há possibilidades de mudanças curriculares ou culturais [...]" (GIMENO SACRISTÁN, 1997, p. 37).

De modo mais simples, a proposta que o autor defende é um exercício constante na escola, no sentido de discutir suas práticas culturais e refletir sobre os modos sacralizados de escolarização aceitos como únicos; um esforço de crítica das práticas naturalizadas e um movimento de construção de espaços compartilhados e práticas possíveis. Muitas escolas têm trabalhado nessa direção e alguns pesquisadores têm apontado importantes possibilidades de mudanças a partir dessas práticas, que não acontecem de forma isolada e não se efetivam sem a participação ativa de todos os atores. 
Para os fins deste artigo e considerando as limitações do texto, destaca-se o trabalho com a elaboração conceitual como uma possibilidade de se pensar práticas convergentes, mediadas e transversais de inclusão escolar.

\section{A elaboração de conceitos: possibilidade de um projeto cultural de escolarização abrangente}

A proposta de trabalho com a elaboração de conceitos pauta-se nos pressupostos da teoria histórico-cultural de Vygotsky, autor que tem um papel fundamental na mudança de concepção sobre as possibilidades de aprendizagem das crianças, notadamente de crianças e jovens com deficiência. $O$ autor considera que o estudo das peculiaridades positivas do comportamento infantil é exigência básica para o problema do desenvolvimento nas investigações. Trata-se de "[...] captar as características reais da conduta da criança em toda a sua plenitude e riqueza de expansão e apresentar o positivo de sua personalidade" (VYGOTSKY, 1995, p. 141).

Mello (2010, p. 730) considera que Vygotsky, ao apontar para a criança um lugar rico de possibilidades, como alguém capaz de estabelecer relações com o mundo, a coloca em uma posição diferente do que ocorre quando esta é compreendida como pobre de possibilidades, como alguém a ser protegido e cuidado em um ambiente isolado, de simulações superficiais e pobres de vivências com a cultura elaborada. Essa questão evidencia a relevância de se reconfigurarem as práticas culturais estabelecidas no trabalho com os alunos com e sem deficiência na escola.

A abordagem de Vygotsky também apresenta elementos para solucionar a polêmica sobre o protagonismo no processo educativo: nem o meio, nem o professor ou a professora, e nem a criança são considerados isoladamente, mas a unidade indivisível da relação que se estabelece entre eles e que se constitui na vivência. Para o autor, a vivência é uma unidade indivisível que sempre se liga àquilo que está localizado fora da pessoa, mas também está relacionada ao modo como a pessoa representa o que vivenciou, ou seja, quais particularidades da sua personalidade se manifestam na particularidade da situação (VYGOTSKY, 2010). 
Ao destacar o meio como fonte do desenvolvimento humano desde a infância, Vygotsky considera que os conteúdos das vivências devem contemplar o acesso ao conjunto da cultura humana nas mais variadas situações de aprendizagem (nesse caso, a escolarização tem relevante papel). "Em cada idade, a criança interpretará, compreenderá, atribuirá sentidos diferentes ao que vê e vive. E nesse processo se apropriará das máximas possibilidades de desenvolvimento humano" (MELLO, 2010, p. 735).

No que se refere às questões do desenvolvimento das funções psicológicas superiores, Vygotsky (2007, p. 58) afirma que "[...] todas as funções superiores originamse das relações reais entre os indivíduos humanos", enfatizando a importância da mediação nas interações da criança com seus pares em todos os meios sociais. Por isso, o foco da proposta centra-se nas interações e nas mediações que contribuem para a elaboração de processos cognitivos mais complexos em crianças nas experiências escolares.

Para promover o crescimento intelectual, imaginativo e afetivo da criança, é necessário o desenvolvimento do pensamento e da linguagem, os quais dependem da evolução da palavra. A criança, desde a mais tenra idade, recebe estímulos (mediação), seja por meio de palavras, de objetos ou de qualquer forma de comunicação, o que vai proporcionando a interação e a compreensão do mundo ao seu redor. A palavra assume, para a criança, uma propriedade do objeto ao nomeá-lo, o que Vygotsky (2008) denomina palavra-objeto. Posteriormente, esta adquire uma estrutura simbólica no processo de evolução, o qual acontece paralelamente ao desenvolvimento do pensamento. Ambos, porém, em vários momentos, se cruzam, e o pensamento torna-se verbal e a fala racional.

Particularmente, em relação aos processos de desenvolvimento do pensamento das crianças com deficiência intelectual, Vygotsky considera que ele ocorre em uma estrutura que é secundária ao defeito. Esse desenvolvimento é considerado incompleto porque resulta muito mais do "isolamento ou exílio" do sujeito da coletividade. Segundo Vygotsky (2012), esse “exílio” transcorre do seguinte modo: 
A raiz de um determinado defeito faz aparecer na criança uma série de particularidades que obstaculizam o desenvolvimento normal da comunicação coletiva, de colaboração e interação dessa criança com as pessoas que a rodeiam. A separação da coletividade ou a dificuldade de desenvolvimento social, por sua vez, determina o desenvolvimento incompleto das funções psíquicas superiores, as quais, quando o curso das coisas é normal, surgem diretamente relacionadas ao desenvolvimento da atividade coletiva da criança. (VYGOTSKY, 2012, p. 223)

Desse modo, a causa do desenvolvimento incompleto das funções psicológicas superiores decorre das dificuldades que a criança com deficiência experimenta em relação à atividade coletiva. E a sua superação depende, portanto, da qualidade da relação que estabelecem com ela. "Assim como é praticamente inútil lutar contra o defeito e suas consequências diretas, é, inversamente, frutífera e promissora a luta contra as dificuldades na atividade coletiva” (VYGOTSKY, 2012, p. 223). Para o autor, “[...] seguir la transformación de las formas colectivas de colaboración em formas individuales de la conducta del niño significa también captar el principio formativo de las funciones psíquicas superiores em su devenir" (VYGOTSKY, 2012, p. 214). As características individuais, portanto, estão intimamente ligadas às trocas que a criança com deficiência estabelece com o coletivo, porque, mesmo o que se considera mais pessoal e individual no ser humano, ele só se constitui por causa da sua relação com o coletivo.

Ao longo do desenvolvimento da criança, a palavra vai assumindo diferentes estruturas até chegar à formação de conceitos. Nesse processo, Vygotsky (2008) distingue três fases com vários estágios, passando pelo sincretismo, o pensamento por complexos e o pensamento por conceitos. No sincretismo, a criança faz associações de forma desorganizada ou sincrética, percebe os objetos isoladamente e os agrupa sem uma lógica sob o significado de uma palavra; no pensamento por complexos, a criança cria elos de relações entre os objetos, de acordo com as associações que estabelece entre eles, caracterizando uma forma coerente de associação. É o início do pensamento objetivo, pois as ligações entre os objetos são concretas e factuais, formando a base para as posteriores generalizações. O pensamento por conceitos, por sua vez, caracteriza-se pelo processo de "[...] abstrair, isolar elementos, e examinar os elementos abstratos separadamente da totalidade da experiência concreta de que fazem parte" (VYGOTSKY, 
2008, p. 95). Esse estágio também possui três subdivisões e o uso da palavra faz parte do processo. Na primeira fase, a criança detém-se mais em algumas características dos objetos do que em outras, elegendo o mais semelhante possível. Na fase seguinte, a que Vygotsky denomina formação de conceitos potenciais, a criança utiliza a percepção e a prática para se referir ao objeto. Na terceira fase, a do pensamento por conceito, a palavra desempenha o papel de sintetizar ou indicar os atributos, é ela que vai “[...] centrar ativamente a atenção, abstrair determinados traços, sintetizá-los e simbolizá-los por meio de um signo" (VYGOTSKY, 2008, p. 101).

Ao dominar as estruturas simbólicas por meio da palavra, fazendo o uso social, as crianças desenvolvem as bases do pensamento e da linguagem, os quais também vão evoluindo de acordo com as vivências e os novos significados da palavra.

Para compreender a formação de conceitos no processo de escolarização, Vygotsky (2008) denominou conceitos cotidianos ou espontâneos e conceitos científicos. Os conceitos cotidianos ou espontâneos são aqueles desenvolvidos a partir das experiências diárias, por meio de enlaces reais-imediatos, mais concretos, estabelecidos pela criança com o meio. Já os conceitos científicos são consequência das experiências principalmente no contexto escolar, de forma consciente, estabelecendo relações mentais ou lógico-verbais para sua elaboração. Eles envolvem, desse modo, todos os conteúdos escolares, sejam eles os de natureza intelectiva, afetiva ou estética.

Esses dois conceitos, embora distintos, influenciam-se constantemente, como afirma Vygotsky:

Fazem parte de um único processo: o desenvolvimento da formação de conceitos, que é afetado por diferentes condições externas e internas, mas que é essencialmente um processo unitário, e não um conflito entre formas antagônicas e mutuamente exclusivas. $O$ aprendizado é uma das principais fontes de conceitos da criança em idade escolar, e é também uma poderosa força que direciona o seu desenvolvimento, determinando o destino de todo o seu desenvolvimento mental. (VYGOTSKY, 2008, p. 107)

Assim, para o desenvolvimento dos conceitos científicos, é fundamental a interação do adulto, mais especificamente do professor para dar as condições necessárias para o seu desenvolvimento, como nos esclarece Fontana: 
Ao utilizar-se das palavras, o adulto (deliberadamente ou não) apresenta à criança significados estáveis e sentidos possíveis no seu grupo social. É na margem das palavras do adulto que a criança organiza sua própria elaboração. [...]. No curso da utilização e internalização dessas palavras e das funções a elas ligadas, a criança aprende a aplicá-las consciente e deliberadamente, direcionando o próprio pensamento. (FONTANA, 1996, p. 123)

Dessa forma, a criança, por meio do pensamento, passa a desenvolver os conceitos, sendo capaz de utilizar a palavra para, além de "[...] representar objetos, também analisá-los, abstrair e generalizar suas características" (LURIA, 1986, p. 36). Não necessita mais do objeto concreto, a palavra designa e acessa os conhecimentos construídos e possibilita a conexão para a aquisição de novos conhecimentos.

Contudo, os estudos de Vygotsky (2008) apontam que a formação de conceitos, que se inicia com todas as experiências desde o início da infância, segue um processo que somente se estabelece e amadurece na adolescência. "É o resultado de uma atividade complexa, em que todas as funções intelectuais básicas tomam parte" (VYGOTSKY, 2008, p. 72). Toda interação e mediação para a resolução de problemas e estimulação do pensamento da criança, portanto, é fundamental para o desenvolvimento dos processos psicológicos do indivíduo, assim como a precariedade desses estímulos pode causar atrasos no desenvolvimento e dificultar a capacidade de elaborar conceitualmente. Por essa razão, os momentos de coletividade quando pautados em práticas educativas de formação de conceitos contribuem para o desenvolvimento da capacidade de generalização e de abstração.

O desenvolvimento de uma proposta dessa natureza requer dos professores, da sala comum de ensino e da SRM não só a utilização de conhecimentos do campo da didática - para propor estratégias pedagógicas que configurem apoio ou suporte aos seus alunos nas mais variadas situações de aprendizagens - como também o domínio de conceitos das diversas áreas do conhecimento e a mobilização dos meios apropriados instrumentos e signos - sem os quais o trabalho não pode ser realizado.

Desse modo, o caráter mediado dos processos psíquicos superiores e a colaboração coletiva de elementos-chave da teoria de Vygotsky (2007) fundamentam a proposta de práticas curriculares de elaboração conceitual. Significa assumir que as 
possibilidades de trabalhar com a elaboração conceitual dos alunos, em particular dos alunos com deficiência, transtornos globais do desenvolvimento e altas habilidades, exigem da escola o uso de "ferramentas ou instrumentos psicológicos" (VYGOTSKY, 2007, p. 93), entre os quais se destacam: a linguagem oral e escrita, o sistema de números e cálculos, as estratégias mnemônicas, as produções artísticas, os diagramas, os mapas, os desenhos e todos os signos estabelecidos por convenção.

A compreensão desses pressupostos pelo professor, no ambiente escolar, culminaria no exercício de uma "pedagogia do coletivo" centro da abordagem históricocultural.

\section{Considerações finais}

Em face das questões apresentadas, as discussões deste artigo buscaram evidenciar as contradições internas que permeiam as diretrizes da política de educação inclusiva para alunos público-alvo da Educação Especial. Essas contradições evidenciam-se especialmente no conjunto de diretrizes estabelecidas, as quais destacam a natureza transversal da Educação Especial em relação a todos os níveis de ensino, mas, por outra via, atribuem ao Atendimento Educacional Especializado um papel secundário no processo de escolarização.

A política define como meta principal fortalecer o modelo educacional inclusivo garantindo o acesso e a permanência, estabelecendo as trocas capazes de promover a participação, o aprendizado e o desenvolvimento dos alunos com deficiência, transtornos

globais do desenvolvimento e altas habilidades/superdotação. Todavia, ela organiza um tipo de serviço especializado que tem a função complementar e/ou suplementar ao processo de escolarização por meio da provisão de recursos pedagógicos e didáticos.

Esse lugar atribuído ao AEE em relação ao processo de escolarização assume outras dimensões no contexto da escola, especialmente se o projeto de escolarização construído passa pela definição rígida dos espaços de aprendizagem como lugares específicos, polarizados e impenetráveis. Desde um espaço individualizado, altamente especializado e instrumentalizado, encontra-se o professor e o aluno da Educação 
Especial e, de outro lado, um espaço coletivo voltado ao ensino do conteúdo, onde, indistintamente, encontra-se o professor da sala comum e todos os seus alunos.

Em um lugar, o tratamento ao conteúdo é também polarizado, dividido em partes e, no outro, os conteúdos esvaziam-se no rol de exercícios, de jogos, de tarefas e de pautas de estudos. Há, no entanto, possibilidades outras de significar essas relações, espaços e lugares que compõem o projeto de escolarização das escolas. A proposta que se vislumbra é o que Gimeno Sacristán (1997) denominou de decodificação das condições de escolarização que supõe falar de formas alternativas aos comportamentos pedagógicos, organizacionais e institucionais sacralizados.

Uma alternativa possível, entre tantas outras experimentadas por muitas escolas que realizam esse movimento de decodificação, seria o trabalho de elaboração de conceitos. Os princípios vygotskianos são a base pela qual se fundamenta esta proposta, visto que não concebem a elaboração de conceitos científicos fora do espaço escolar, local formal para esse fim, que, necessariamente, deve contar com a colaboração de um adulto - o professor - e grupos pequenos - os colegas de classe.

Partindo desse pressuposto, a escola inclusiva constitui-se neste espaço privilegiado para a elaboração conceitual de todos os alunos da classe. Essa compreensão passa por compreender o projeto de escolarização como a busca do nexo entre a colaboração coletiva e o desenvolvimento das funções psicológicas superiores, entre o desenvolvimento da coletividade e a personalidade do sujeito, entre a mediação e a linguagem como comunicação e expressão do pensamento (VYGOTSKY, 2007, 2008, 2012), todos em constante realização, nos diferentes espaços que constituem a escola. Desse modo, o processo de elaboração de conceitos, a colaboração coletiva e a linguagem são centrais no desenvolvimento dos alunos com e sem deficiências e, por essa razão, o projeto de escolarização que se almeja não pode prescindir deles. 


\section{Referências}

BALL, Stephen J. Education reform: a critical and post-structural approach. Buckingham, UK: Open University Press, 1994.

BALL, Stephen J.; MAGUIRE, Meg; BRAUN, Annette. How schools do policy: policy enactments in secondary schools. London; New York: Routledge; Taylor \& Francis Group, 2012.

BARROSO, João. Cultura, cultura escolar, cultura de escola. In: ACERVO digital da Unesp.. São Paulo: UNESP, 23 de jan., 2013. Disponível em:

< http://www.acervodigital.unesp.br/handle/123456789/65262>.

Acesso em: 20 abr. 2016.

BRASIL. Decreto $N^{\circ} 7.611$, de 17 de novembro de 2011. Dispõe sobre a educação especial, o atendimento educacional especializado e dá outras providências. Diário Oficial [da]

República Federativa do Brasil, Poder Executivo, Brasília, DF, 18 nov. 2011. Seção 1, n. 221, p. 12.

BRASIL. Política Nacional de Educação Especial na perspectiva da educação inclusiva. Brasília: MEC/SEESP, 2008.

DUSSEL, Inés. Es el curriculum escolar relevante en la cultura digital? Debates y desafíos sobre la autoridad cultural contemporânea. Revista Archivos Analíticos de Políticas Educativas [online], v. 22, n. 24, abr. 2014. Disponível em:

<http://epaa.asu.edu/ojs/article/download/1586/1228>. Acesso em: 20 abr. 2016.

FONTANA, R. A. C. Mediação Pedagógica na sala de aula. Campinas, SP: Autores associados, 1996. (Coleção Educação Contemporânea).

GARCIA, Rosalba Maria Cardoso. Política de educação especial na perspectiva Inclusiva e a formação docente no Brasil. Revista Brasileira de Educação, Rio de Janeiro, v. 18, n. 52, p. 101239, 2013.

GIMENO SACRISTÁN, José. Escolarização e cultura: a dupla determinação. In: SILVA, Luiz Heron da. et al. (Orgs.). Novos mapas culturais, novas perspectivas educacionais. Porto Alegre: Sulina, 1997. p. 34-57.

HOSTINS, Regina Célia Linhares; JORDÃO, Suellen Garay Figueiredo. Política de inclusão escolar e práticas curriculares: estratégias pedagógicas para elaboração conceitual do público alvo da educação especial. Arquivos Analíticos de Políticas Educacionais [online], v. 23, n. 28, 2014. Disponível em: <http://epaa.asu.edu/ojs/article/download/1661/1574>. Acesso em: 20 abr. 2016.

LUNARDI, Geovana Mendonça. Quando não aprender importa: as práticas docentes das diferenças apresentadas por alunos na aprendizagem de conteúdos escolares. In: Actas dos ateliers do V Congresso Português de Sociologia: Sociedades contemporâneas; reflexividade e acção. Atelier: Educação e Aprendizagens. Portugal, 2004. p. 62-70. 
LUNARDI, Geovana Mendonça. Nas trilhas da exclusão: as práticas curriculares de sala de aula como objeto de estudo. In: BUENO, José Geraldo Silveira; LUNARDI-MENDES, Geovana Mendonça; SANTOS, Roseli Albino. (Orgs.). Deficiência e escolarização [recurso eletrônico]: novas perspectivas de análise. 2. ed. Araraquara: Junqueira e Marin, 2012. p. 122-138.

LURIA, Alexander Romanovich. Pensamento e linguagem: as últimas conferências de Luria. Tradução D. M. Lichtenstein e M. Corso. Porto Alegre: Artes Médicas, 1986.

MELLO, Sueli Amaral. A questão do meio na pedologia e suas implicações pedagógicas. Psicologia USP, São Paulo, v. 21, n. 4, p. 727-739, 2010.

ORGANIZAÇÃO DOS ESTADOS AMERICANOS. Convenção Interamericana para a Eliminação de Todas as Formas de Discriminação contra as Pessoas Portadoras de Deficiência. Guatemala: OEA, 1999.

UNESCO. Declaração mundial sobre educação para todos: satisfação das necessidades básicas de aprendizagem. Jomtien, UNESCO, 1990.

UNESCO. Declaração de Salamanca. Conferência Mundial sobre Necessidades Educativas Especiais: acesso e qualidade. Salamanca, Espanha: UNESCO, 1994.

VYGOTSKY, Lev Semionovitch. A questão do meio na pedologia. Tradução M. P. Vinha. Instituto de Psicologia: Universidade de São Paulo, 2010.

VYGOTSKY, Lev Semionovitch. Obras escogidas (Vol. 3). Madrid: Visor, 1995.

VYGOTSKY, Lev Semionovitch. A formação social da mente. Organização de Michael Cole et. al. Tradução José Cipolla Neto, Luís Silveira Menna Barreto e Solange Castro Afeche. 7. ed. São Paulo: Martins Fontes, 2007.

VYGOTSKY, Lev Semionovitch. Pensamento e linguagem. Tradução Jefferson Luiz de Camargo. 4. ed. São Paulo: Martins Fontes, 2008.

VYGOTSKY, Lev Semionovitch. Obras escogidas - V. Fundamentos de defectología. Madrid: Machado Grupo de Distribuición, S. L., 2012. 